Clarkson, E. M., McDonald, S. J, and de Wardener, H. E. (1966). Clinical Science, 30, 425 .

Ford, F. J. (1931). Archives of Diseases in Childhood, 6, 209.

Jones, K. H., and Fourman, P. (1963). Lancet, 2, 119.

Jones, J. H., Peters, D. K., Morgan, D. B., Coles, G. A., and Mallick, N. P. (1967). Quarterly fournal of Medicine, 36, 301.

King, J. S., Jackson, R., and Ashe, B. (1964). Investigative Urology, 1,
Kleeman, C. R., Bohannan, J., Bernstein, D., Ling, S., and Maxwell, M. H. (1964). Proceedings of the Society of Experimental Biology and Medicine, 115, 29.

Meulemeester, F. de (1960). Archives française de Paediatrie, 17, 647.

Phillips, M. J., and Cooke, J. N. C. (1967). Lancet, 1, 1354.

Schreiter, G., and Mascher-Koch, M. (1966). Monatsschrif: fïr Kinderheilkunde, 114, 432.

Stanbury, S. W., and Lumb, G. A. (1962). Medicine, 41, i.

Walser, M. (1961). American fournal of Physiology, 200, 1099.

\title{
Handling of Induced Hypercalcaemia in Hyperthyroidism
}

\author{
P. LIM,* M.B., B.CHIR., M.R.C.P. ; E. JACOB, $\dagger$ PH.D. ; O. T. KHOO, $\ddagger$ M.D., F.R.C.P.ED., F.R.A.C.P.
}

\begin{abstract}
Summary : The mean serum calcium of 13 hyperthyroid patients was found to be significantly higher than that of controls matched for sex and age, though none of the patients' values were outside the normal range. Nevertheless, these patients responded very promptly to hypercalcaemia (induced by an intravenous calcium load), and their serum calcium returned to normal much more rapidly compared with the matched controls. There was also increased retention of intravenous calcium load, possibly owing to increased calcitonin production. Calcium infusion may be useful in treating bone diseases in which increased bone resorption exceeds bone accretion.
\end{abstract}

\section{Introduction}

Hypercalcaemia in hyperthyroidism not associated with hyperparathyroidism, though rare, has been reported (Epstein et al., 1958 ; Kleeman et al., 1958). Adams et al. (1967) found the mean serum calcium of hyperthyroid patients to be higher $(P<0.01)$ than that of a group of normal subjects matched for sex and age, and since the mean serum albumin concentration of these patients was less $(P<0.001)$ than that of the normal subjects these workers deduced that the serum concentration of the biologically important ionized calcium in hyperthyroid patients was greater than normal. This was confirmed by Frizel et al. (1967), who directly measured serum ionized calcium in hyperthyroid patients.

In view of the established presence of hypercalcaemia in hyperthyroidism we have undertaken a study of the homoeostatic control of plasma calcium in this condition. Adams et al. (1967) have studied the response to induced hypocalcaemia. In the present investigation the response to induced hypercalcaemia is investigated.

\section{Materials and Methods}

(1) In 13 patients (seven males, six females) with untreated hyperthyroidism established clinically and by radioactive iodine uptake, changes in serum calcium were studied following an infusion of calcium. The patients were aged from 16 to 58 years and had no evidence of any concomitant illness. They were matched for sex and age with 13 normal controls.

Patients and controls were each given an intravenous calcium load in the form of calcium gluconate; blood was taken without venous stasis for serum calcium estimation just before infusion

* Lecturer in Clinical Medicine, University of Singapore. + Biochemist, General Hospital, Singapore.

$¥$ Professor of Clinical Medicine, University of Singapore. (zero hour) and at 4, 8, 12, and 24 hours after the start of infusion. Both the zero-hour and 24-hour specimens were of taken with the subjects fasted overnight. The amount of calcium gluconate used was calculated on the basis of body $\vec{v}$ weight (15 mg. of elemental calcium per kg. body weight) $ᄋ$ and was infused, diluted in $500 \mathrm{ml}$. of $5 \%$ dextrose, evenly $N$ over four hours. All subjects were put on a $600-\mathrm{mg}$. calcium diet during the test. Serum calcium was estimated in duplicate $\mathbb{D}$ with the atomic absorption spectrophotometer (SP 90, Unicam); the error between duplicate estimations never $\frac{7}{0}$ exceeded $0.1 \mathrm{mg} . / 100 \mathrm{ml}$.

The overall assessment of each subject's response to hyper- $\overrightarrow{\mathscr{\theta}}$ calcaemia was made by estimating the tolerance area. This is the area below the straight lines joining the five points on $\square$ the time versus serum calcium graph (Fig. 1), above the horizontal line at the preinfusion serum calcium value. The area is represented by the formula:

$$
\text { Area }=\left(b+c+2 d+\frac{3}{2} e-5 \frac{1}{2} a\right) \text { units }
$$

where " $a$ " is serum calcium at zero hour, " $b$ " at fourth hour, $\frac{0}{3}$ " $c$ " at eighth hour, " $d$ " at twelfth hour, and "e" at twenty-fourth hour. Where b, c, d, or e is less than a a correction factor will have to be applied to the formula. Thus, if $e$ is less than a the formula is modified as follows:

$$
\text { Area }=b+c+2 d+\frac{3}{2} e-5 \frac{1}{2} a+\frac{3(a-e)^{2}}{2(d-e)} \text { units }
$$

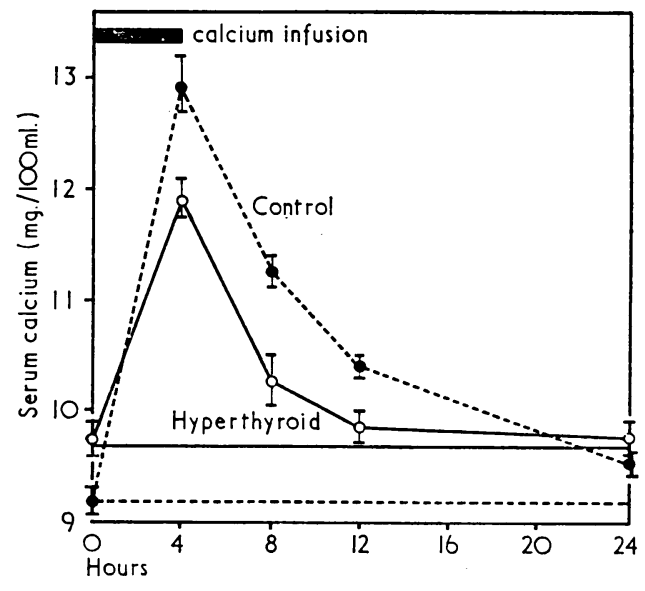

FIG. 1.-Effect on serum calcium of an infusion of calcium, shown as mean \pm S.E. of mean for hyper. thyroid patients and controlled subjects.

(2) In another group of six untreated hyperthyroid patients and six normal controls a test of calcium retention was carried out. Patients were put on a low $(150 \mathrm{mg}$.) calcium diet for four days, and urine was collected daily for estimation of 
24-hour urinary excretion of calcium. On the fourth day an infusion of calcium gluconate $(15 \mathrm{mg}$. of calcium $/ \mathrm{kg}$. body weight) was given over four hours. The amount retained, expressed as percentage of infused load, is calculated by subtracting from the infused load $(\mathrm{L})$ the difference between the 24-hour urinary calcium excretion (A) of the day of infusion and that $(B)$ of the previous day-that is, $L-(A-B)$.

\section{Results}

The patients' mean preinfusion serum calcium, $9 \cdot 72( \pm$ S.E. of mean 0.16$) \mathrm{mg} . / 100 \mathrm{ml}$., is significantly higher $(\mathrm{P}<0.01)$ than that of their matched controls, $9 \cdot 19$ ( \pm S.E. of mean $0 \cdot 12$ ) mg. $109 \mathrm{ml}$. (Fig. 1). Yet at the fourth hour, when the highest serum calcium occurs, the patients' mean serum calcium, 11.9 $( \pm$ S.E. of mean 0.13$) \mathrm{mg} . / 100 \mathrm{ml}$., is actually lower $(0.001<$ $\mathrm{P}<0.01$ ) than that of the controls, 12.9 ( \pm S.E. of mean 0.26 ) mg. $/ 100 \mathrm{ml}$. Even at eighth and twelfth hours the patients' mean serum calcium remains significantly lower $(0.001<\mathrm{P}<$ 0.01 and $0.01<\mathrm{P}<0.05$ respectively) than the corresponding figures in the controls.

For the patients there is already no statistically significant difference between the mean twelfth-hour serum calcium, 9.86 $( \pm$ S.E. of mean 0.12$) \mathrm{mg} . / 100 \mathrm{ml}$, and the mean preinfusion serum calcium, $9.72( \pm$ S.E. of mean 0.16$) \mathrm{mg}$. $100 \mathrm{ml}$. It was no surprise, therefore, that their mean twenty-fourth-hour serum calcium, 9.75 ( \pm S.E. of mean 0.16$) \mathrm{mg} . / 100 \mathrm{ml}$., was even closer to the mean preinfusion level. At the twenty-fourth hour three patients had serum calcium values below and five had values equal to their respective preinfusion figures. In three patients the eighth-hour serum calcium values were lower than their preinfusion figures by $0.3,0.5$, and $0.4 \mathrm{mg} . / 100 \mathrm{ml}$. respectively, and the twelfth-hour serum calcium values lower than their preinfusion figures by $0.3,0.2$, and $0.5 \mathrm{mg} . / 100 \mathrm{ml}$. respectively.

As for the controls, even the mean twenty-fourth-hour serum calcium, $9.53( \pm$ S.E. of mean 0.11$) \mathrm{mg} . / 100 \mathrm{ml}$. is still significantly higher $(\mathbf{P}<0.05)$ than the mean preinfusion level, $9 \cdot 19$ $( \pm$ S.E. of mean 0.12$) \mathrm{mg} . / 100 \mathrm{ml}$., and none in the course of the 24 hours observed reached the preinfusion value.

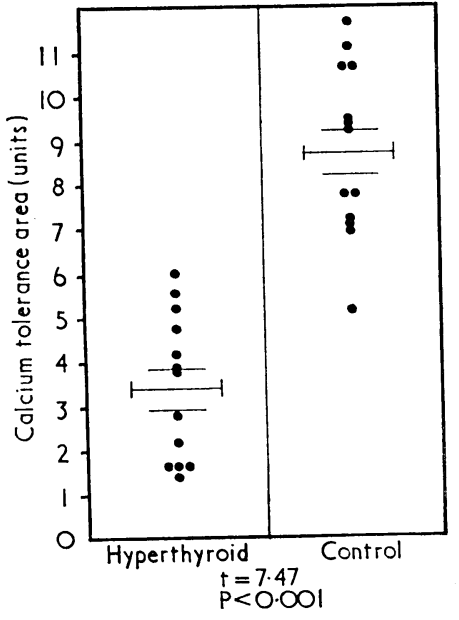

FIG. 2-Mean calcium tolerarae area ( $\perp$ S.E. of mean) of hype:thyroid patients compared with that thyroid patients compared with that
of matched controls. Calcium tole:ance area is expressed in arbitra: $y$ units (see text)

The difference in the response to intravenous calcium-loading between the two groups is clearly brought out by computing the calcium tolerance area (Fig. 2). Hyperthyroid patients have significantly smaller $(P<0.001)$ areas than their matched controls, the mean for the patients being $3.4( \pm$ S.E. of mean 0.46 ) units and that for the controls 8.7 ( \pm S.E. of mean 0.54$)$ units.
The mean percentage of calcium retained following an infused calcium load is 59.3 ( \pm S.E. of mean 1.4 ) for the six untreated hyperthyroid patients and 37.9 ( \pm S.E. of mean 1.2) for the six normal controls. There is an obvious statistical difference between these two values $(P<0 \cdot 001)$.

\section{Discussion}

Relative hypercalcaemia of hyperthyroidism is not due to parathyroid overactivity (Adams et al., 1967). These authors, however, observed a more rapid return of serum calcium to the initial level following edetic-acid-induced hypocalcaemia, and they believed that excess thyroxine in the patients had accelerated the removal of calcium from bone. There is evidence from the clinical observations of Aub et al. (1932) and Cope and Donaldson (1937) that thyroxine can mobilize calcium from bone in the absence of the parathyroid glands. Jowsey (1966), using quantitative microradiography, found increased bone resorption in hyperthyroidism, confirming results of tracer studies by Eisenberg and Gordan (1961) and Krane et al. (1956). Adams and Jowsey (1967) clearly demonstrated increased bone resorption in dogs made hyperthyroid with thyroxine, and showed that the increased bone resorption is independent of the parathyroid glands. They believe that the tendency to hypercalcaemia in hyperthyroidism is the result of increased bone resorption. Excess thyroxine would appear to have an important influence on plasma calcium in hyperthyroidism.

The physiological role of calcitonin in calcium homoeostasis has been established (Sturtridge and Kumar, 1968). The regulation of plasma calcium is normally brought about by a fine balance between calcitonin on the one hand and parathyroid extraci on the other (Foster, 1968). Hypercalcaemia arising from hyperthyroidism (Frizel et al., 1967) would be expected to suppress the parathyroid glands and to stimulate the calcitonin-producing apparatus. Suppression of the parathyroid has been indirectly shown (Adams et al., 1967). Hypercalcaemia induced in this study would further suppress the parathyroid glands and stimulate the $\mathrm{C}$ cells of the thyroid gland, but the extent of suppression and stimulation would probably be less than in normal controls, in whom the parathyroid glands and the $C$ cells were not initially suppressed and stimulated respectively. Calcium tolerance would be poor in hyperthyroidism compared with that of the normal, but in this study the patients were found to deal much more effectively with hypercalcaemia than their matched controls. This finding is actually consistent with that of Krane et al. (1956), who found after intravenous administration of ${ }^{45} \mathrm{Ca}$ that the specific activity of serum declined more rapidly and to lower levels than in euthyroid controls. This could be explained by the presence of larger calcium compartment sizes which these authors demonstrated.

The influence of calcitonin on the handling of hypercalcaemia in hyperthyroid patients remains to be defined. That induced hypercalcaemia causes a rise in plasma calcitonin level has been clearly shown in normal subjects (Gudmundsson et al., 1969). Mittleman et al. (1967) found that the hypocalcaemic effect of calcitonin on plasma calcium is positively related to the prevailing rate of bone turnover. This is understandable, as calcitonin acts primarily by inhibiting bone resorption (Aliapoulios et al., 1966). In the presence of calcitonininhibited bone resorption the prevailing increased bone accretion rate would lower plasma calcium more rapidly and to a greater extent than if the accretion rate was normal or subnormal. The work of Krane et al. (1956) and Eisenberg and Gordan (1961) had clearly demonstrated an increased bone turnover rate in hyperthyroidism, with increased bone resorption exceeding increased bone accretion. Furthermore, Bijvoet et al. (1968) observed that the hypocalcaemic effect of a given amount of calcitonin is greater in hyperthyroid patients than in normal 
controls. These findings could account for the nature of our patients' response to hypercalcaemia. Our patients' calcitonin production in response to hypercalcaemia need not exceed that of the normal to achieve the prompt control of hypercalcaemia seen. Whether or not calcitonin production is actually greater than normal in hyperthyroidism needs to be confirmed by assay of the hormone itself.

Our finding of increased retention of calcium load is consistent with the greater-than-normal rate of bone accretion in hyperthyroidism in the presence of induced hypercalcaemia. Clerkin et al. (1964) also found increased calcium retention in hyperthyroid patients, but they interpreted this to indicate the presence of osteomalacia. It is true that in osteomalacia, where there is inadequate mineralization of bone due to calcium deficiency, an avid uptake of calcium by bone following an infused calcium load could itself influence the rate of return of serum calcium to its initial level. There is, however, abundant evidence that the bone changes in hyperthyroidism are not those of osteomalacia (Osterberg and Mills, 1932 ; Jowsey, 1966 ; Adams et al., 1967). This is supported by results of tracer stadies by Krane et al. (1956) and Eisenberg and Gordan (1961).

The results of this study suggest that in bone disease in which increased bone resorption exceeds increased bone accretion, such as hyperthyroid osteoporosis (Krane et al., 1956; Eisenberg and Gordan, 1961 ; Jowsey, 1966 ; Adams and Jowsey, 1967), Paget's disease (Nagant de Deuxchaisnes and Krane, 1964 ; Jowsey, 1966), and acromegaly (Eisenberg and Gordan, 1961), calcium infusion might be a useful therapeutic measure. By indirectly inhibiting the prevailing increased bone resorption in the presence of increased bone accretion, calcium infusion greatly enhances net bone accretion as our results suggest, and may lead to healing of bone itself. Moreover, hypercalcaemia induced by calcium infusion in these circumstances, as shown by our results, is relatively mild and shortlived-a cecided advantage. This would not be so if bone accretion rate is normal in the presence of increased bone resorption as in postmenopausal and senile osteoporosis (Lafferty et al., 1964), in which hypercalcaemia would be expected to be as prolonged as in the normal. If shown to be effective and safe, calcium infusion would present a significant advance in the treatment of those bone diseases in which kinetic studies indicate high turnover rate with increased bone resorption exceeding increased bone accretion.

\section{REFERENCES}

Adams, P. H., and Jowsey, J. (1967). Endocrinology, 81, 735.

Adams, P. H., et al. (1967). Quarterly fournal of Medicine, 36, 1.

Aliapoulios, M. A.., Goldhaber, P., and Munson, P. L. (1966). Soience, $151,330$.

Aub, J. C., Abright, F., Bauer, W., and Rossmeisl, E. (1932). Fournal of Clinical Investigation, 11, $21 i$.

Bijvoet, O. L. M., van der Sluys Veer, J., and Jansen, A. P. (1968) Lancet, 1, 876.

Clerkin, E. P., Haas, H. G. Mintz, D. H., Meloni, C. R., and Canary, J. J. (1964). Metabolism, 13, 161.

Cope, O., and Donaldson, G. A. (1937). Foumal of Clinical Investigation, 16, 329.

Eisenberg, E., and Gordan, G. S. (1961). Fournal of Clinical Investiga-

tion, 40, 1809.
Epstein, F. H., Freedman, L. R., and Levitin, H. (1958). New England Fournal of Medicine, 258, 782.

Foster, G. V. (1968). Postgraduate Medical foumal, 44, 411.

Frizel, D., Malleson, A., and Marks, V. (1967). Lancet, 1, 1360.

Gudmundsson, T. V., et al. (1969). Lancet, 1, 443.

Jowsey, J. (1.966). American fournal of Medicine, 40, 485.

Kleeman, C. R., Tuttle, S., and Bassett, S. H. (1958). Fournal of Clinica Endocrinology and Metabolism, 18, 477.

Krane, S. M., Brownell, G. L., Stanbury, J. B., and Corrigan, H. (1956). fournal of Clinical Investigation, 35, 874.

Lafferty, F. W., Spencer, G. E., and Pearson, O. H. (1964). In Dynamic Studies of Metabolic Bone Disease, edited by O. H. Pearson and G. F. Joplin, p. 101. Oxford, Blackwell.

Mittleman, R., Chausmer, A., Bellavia, J., and Wallach, S. (1967). Endocrinology, 81, 599.

Nagant de Deuxchaisnes, C., and Krane, S. M. (1964). Medicine, 43, 233.

Osterberg, A. E., and Mills, R. G. (1932). American fournal of Medical Sciences, 184, 399.

Sturtridge, W. C., and Kumar, M. A. (1968). Lancet, 1, 725.

\title{
Maintenance of Silastic-Teflon Shunts for Intermittent Haemodialysis
}

\author{
C. S. MCINTOSH,* M.B., CH.B.; J. C. PETRIE, $\dagger$ M.B., M.R.C.P. ; M. MACLEOD, $\ddagger$ M.D., F.R.C.P.ED.
}

\begin{abstract}
Summary: The occurrence of infection in the tissues $D$ surrounding external arteriovenous shunts was studied and the important relationship of pyogenic infection to clotting was confirmed. The local application of fusidic acid tulle and lanolin greatly reduced the occurrence of both infection and clotting and the need for cannula replacement.

Urokinase used for declotting shunts when standard procedures had failed, restored blood flow whether clotting was related to infection or to local vascular factors. This treatment is not advised when clotting is associated with a local abscess, as it may make cannula replacement necessary. Severe local vascular factors, such as metastatic calcification, Raynaud's phenomenon, and venous stenosis, may lead to poor blood flow, so that despite clot lysis elective cannula replacement or the creation of a subcutaneous arteriovenous fistula is required.
\end{abstract}

* Medical Registrar, Aberdeen General Hospitals.

t Lecturer in Therapeutics, University of Aberdeen.

¥ Reader in Medicine, Department of Medicine, University of Aberdeen.

\section{Introduetion}

Intermittent haemodialysis is a comparatively straightforward procedure when undertaken with suitable facilities after adequate training. The commonest problems are concerned with the external Silastic-Teflon shunt (Pendras and Smith, 1966). Patients are discouraged and heavy deraands made on the staff by recurring local infection (Martin et al., 1967), repeated clotting (Wing et al., 1967), and frequent replacement of the shunt (Ramirez et al., 1966). Many units are therefore turning to subcutaneous arteriovenous fistulae (Brescia et al., 1966), despite their drawbacks for some patients who are dialysed at home.

In this paper we report the effect of a number of simple procedures on the reduction of pyogenic infection and clotting and the value of urokinase in declotting cannulae by fibrinolysis.

\section{Patients and Methods}

Ten patients with irreversible renal failure were studied over a period of 128 patient-months. Six patients were fully and 